\title{
Oxidative Depolymerization of Kraft Lignin for Microbial Conversion
}

Abdelaziz, Omar Y.; Ravi, Krithika; Mittermeier, Fabian ; Meier, Sebastian; Riisager, Anders; Lidén, Gunnar; Hulteberg, Christian P.

Published in:

A C S Sustainable Chemistry \& Engineering

Link to article, DOI:

10.1021/acssuschemeng.9b01605

Publication date:

2019

Document Version

Publisher's PDF, also known as Version of record

Link back to DTU Orbit

Citation (APA):

Abdelaziz, O. Y., Ravi, K., Mittermeier, F., Meier, S., Riisager, A., Lidén, G., \& Hulteberg, C. P. (2019). Oxidative Depolymerization of Kraft Lignin for Microbial Conversion. A C S Sustainable Chemistry \& Engineering, $7(13)$, 11640-11652. https://doi.org/10.1021/acssuschemeng.9b01605

\section{General rights}

Copyright and moral rights for the publications made accessible in the public portal are retained by the authors and/or other copyright owners and it is a condition of accessing publications that users recognise and abide by the legal requirements associated with these rights.

- Users may download and print one copy of any publication from the public portal for the purpose of private study or research.

- You may not further distribute the material or use it for any profit-making activity or commercial gain

- You may freely distribute the URL identifying the publication in the public portal 


\title{
Oxidative Depolymerization of Kraft Lignin for Microbial Conversion
}

\author{
Omar Y. Abdelaziz, ${ }^{\dagger, \ddagger \odot}$ Krithika Ravi, ${ }^{\dagger}$ Fabian Mittermeier, ${ }^{\dagger}$ Sebastian Meier, ${ }^{\ddagger \odot}$ Anders Riisager, ${ }^{\ddagger}$
} Gunnar Lidén, ${ }^{\dagger}$ and Christian P. Hulteberg* ${ }^{*} \dagger^{+}$

${ }^{\dagger}$ Department of Chemical Engineering, Lund University, Naturvetarvägen 14, 22100 Lund, Sweden

${ }^{\ddagger}$ Department of Chemistry, Technical University of Denmark, Kemitorvet 207, 2800 Kgs. Lyngby, Denmark

\section{Supporting Information}

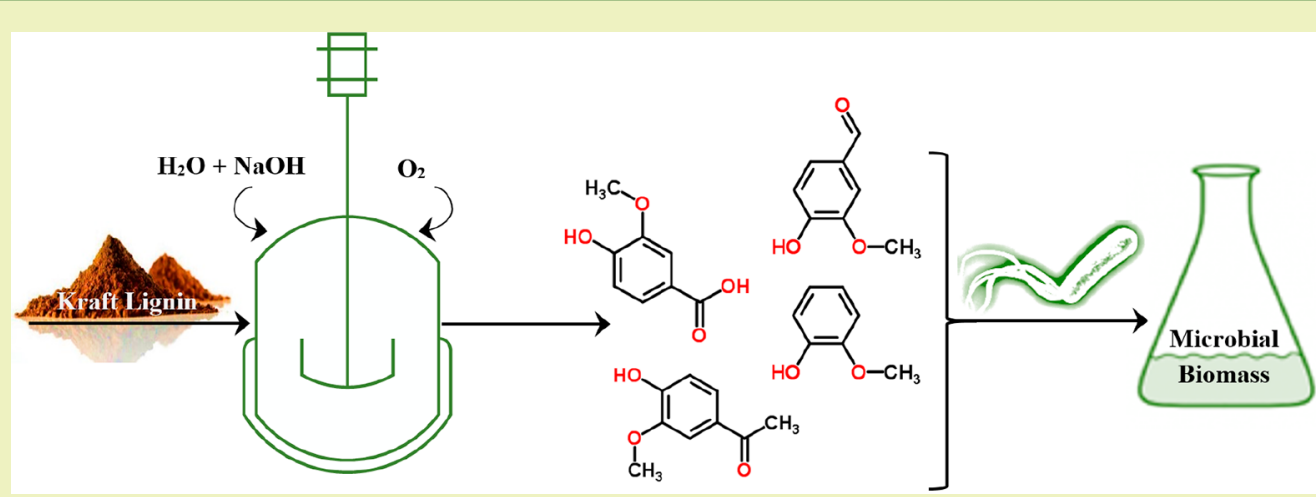

ABSTRACT: The valorization of lignin is being increasingly recognized as crucial to improve the economic viability of integrated biorefineries. Because of its inherent heterogeneity and recalcitrance, lignin has been treated as a waste product in the pulp and paper industry, but new technologies are now being explored to transform lignin into a sustainable resource and enhance its value chain. In the present study, alkaline oxidative depolymerization was investigated as a potential form of pretreatment to enable further biological conversion of LignoBoost kraft lignin (LB). LB lignin oxidation reactions were studied at various temperatures $\left(120-200{ }^{\circ} \mathrm{C}\right)$ and $\mathrm{O}_{2}$ partial pressures $(3-15 \mathrm{bar})$ to identify the optimal conditions for obtaining a biocompatible, oxidatively depolymerized lignin (ODLB) stream. The low molecular weight compounds resulting from this treatment consisted mainly of aromatic monomers and carboxylic acids. The highest yield of aromatic monomers, $3 \mathrm{wt} \%$, was obtained at $160{ }^{\circ} \mathrm{C}$ and 3 bar $\mathrm{O}_{2}$. The yield of carboxylic acids increased with both increasing temperature and $\mathrm{O}_{2}$ pressure, exceeding $13 \%$ under the harshest conditions investigated. The growth of four aromatic-catabolizing bacterial strains was examined on reaction product mixtures, all of which showed growth on agar plates utilizing ODLB as the sole source of carbon and energy. Rhodococcus opacus and Sphingobium sp. SYK-6 were found to consume most of the aromatic monomers present in the ODLB (e.g., vanillin, vanillate, acetovanillone, and guaiacol). The findings of this study indicate that pretreatment by oxidative depolymerization has potential in the biological valorization of technical lignin streams, for the production of valuable chemicals and materials.

KEYWORDS: Alkaline oxidation, Aromatic monomers, Bacterial conversion, Lignin valorization, LignoBoost, Softwood, Sustainable resources

\section{INTRODUCTION}

Lignin is considered the most abundant terrestrial noncarbohydrate biopolymer, comprising 15-30 wt \% of dry lignocellulosic biomass. $^{1-4}$ As a raw material, lignin has considerable potential in a lignocellulosic biorefinery but also poses significant challenges. ${ }^{5,6}$ The valorization of lignin would improve the economics of biomass conversion, as the use of lignin today is primarily limited to combustion for energy recovery in pulp mills. Apart from economic considerations, environmental concerns must also be taken into account in the development of future lignin biorefinery concepts, and the principles of green chemistry should be adopted in lignin processing and conversion. ${ }^{7}$
Kraft pulping is the process most commonly used to produce paper pulp worldwide. ${ }^{8}$ In this operation, wood is transformed into wood-pulp by treatment with a $\mathrm{Na}_{2} \mathrm{~S} / \mathrm{NaOH}$ solution, socalled white liquor, at temperatures of $155-175{ }^{\circ} \mathrm{C}$ for several hours, ${ }^{9}$ during which $90-95 \%$ of the lignin in the starting material is dissolved. ${ }^{10}$ The annual production of kraft pulp worldwide is about 130 million tons, ${ }^{11}$ and the kraft lignin black liquor generated represents the largest share of the biofuel sector in the Swedish and the Finnish energy matrices. ${ }^{12}$ LignoBoost is a well-proven technology for commercial-scale kraft lignin

Received: March 21, 2019

Revised: $\quad$ May 6, 2019

Published: June 13, 2019 
recovery. ${ }^{13,14}$ This process enables high-purity lignin production with rather low ash and carbohydrate contents. Considering the dominant role of kraft processes, ${ }^{15}$ and that lignin is an abundant, inexpensive resource of aromatics, new applications based on utilizing kraft lignin from black liquor are desirable.

The challenges associated with the utilization and conversion of (technical) kraft lignin into bulk or specialty chemicals are the result of the highly complex and heterogeneous nature of this biomacromolecule. The condensed structures, highly recalcitrant linkages, and presence of sulfur render kraft lignin a difficult raw material to process and transform. ${ }^{16,17}$ The development of efficient methods of depolymerization will thus play a central role in the valorization of kraft lignin for the production of valuable platform chemicals. ${ }^{18}$

The depolymerization of technical lignin is a demanding task, as processing, such as kraft cooking, usually results in significant changes in the lignin structure. Condensation of reactive intermediate motifs via $\mathrm{C}-\mathrm{C}$ bond formation and the cleavage of aryl ether bonds (predominantly $\beta$-O-4 linkages) ${ }^{4,19}$ during the cooking process make it structurally different from native lignin and more resistant to break down. Lignin depolymerization approaches reported in the literature include thermal, ${ }^{20}$ biochemical, ${ }^{21-23}$ acid-catalyzed, ${ }^{24}$ base-catalyzed, ${ }^{25-27}$ oxidative, $^{28-31}$ and reductive ${ }^{32,33}$ methods. Among these, the oxidation approach represents an energy-efficient means of lignin decomposition, while generating targeted products in a selective way, including valuable chemicals such as phenolic aldehydes, phenolic acids, and carboxylic acids. ${ }^{34-37}$ Oxidation also allows the $\mathrm{pH}$ of reaction product mixtures to be controlled, by monitoring the yields of aliphatic carboxylic acids, while reducing the recalcitrance of lignin structures. Therefore, chemochemical oxidative depolymerization may be a valuable pretreatment step in biochemical lignin conversion.

Microbial funneling, i.e., the use of converging microbial pathways toward a common intermediate, is a promising approach to tackle the multitude of compounds in ligninderived streams. ${ }^{38-40}$ Several microorganisms have been utilized in previous studies for the bioconversion of pretreated lignin streams. Microbial growth and the accumulation of intracellular storage compounds have been investigated in alkaline-pretreated liquor from corn stover using several bacteria. In a study including 14 bacterial strains, Amycolatopsis sp., Pseudomonas putida, and Acinetobacter ADP1 were reported to depolymerize and catabolize $30 \%$ of the initial lignin present. ${ }^{22}$ In another recent study on the conversion of depolymerized kraft lignin employing base catalysis, Pseudomonas fluorescens was reported to break down high molecular weight lignin, and Rhodococcus opacus was reported to consume most of the available aromatic monomers. ${ }^{41}$ The intracellular accumulation of lipids in $R$. opacus growing on oxygen-treated kraft lignin has also been assessed, showing an accumulation of $0.07 \mathrm{~g} / \mathrm{L}$ microbial lipids, mainly composed of palmitic and stearic acids. ${ }^{42}$ The ability of bacterial species to metabolize depolymerized lignin depends on several factors, including the plant origin of the lignin, whether the lignin is technical or native, the type and severity of pretreatment, and the complexity of the product mixture. It is therefore important to screen for, and select, the appropriate microorganism for a given substrate. In contrast, the mode of lignin separation, such as LignoBoost, LignoForce, or similar commercially available methods, is not believed to greatly influence the suitability with respect to biocompatibility.

In the present work, alkaline oxidative depolymerization of an industrial lignin stream (LignoBoost softwood kraft) was examined, and the effect of reaction severity on molecular weight distribution and the formation of low molecular weight products was evaluated. Microbial conversion of the depolymerized products was further assessed to identify the treatment conditions that provided a biocompatible product stream with the potential for bacterial conversion. The growth of four aromatic-catabolizing bacterial species: $P$. putida KT2440, $P$. fluorescens, R. opacus, and Sphingobium sp. SYK-6, on various product mixtures was evaluated. High-cell-density liquid cultivations were performed using lignin treated at a selected condition to analyze the consumption of monomers and possible effects on molecular weight by enzymatic degradation. The study demonstrates the potential of oxidative depolymerization as a means of pretreatment toward the microbial conversion of technical lignin and is, to the best of our knowledge, the first integrated study exploring the parameter space of oxidative depolymerization and the resulting effect on lignin conversion by multiple bacterial species.

\section{EXPERIMENTAL SECTION}

Chemicals and Materials. LignoBoost lignin (LB), a softwood kraft technical lignin, was obtained as a dry powder from Innventia's pilot plant located in Bäckhammar, Sweden. Oxygen gas $\left(\mathrm{O}_{2} \geq 99.5 \%\right)$ was supplied by AGA Industrial Gases, Denmark. The bacterial species Pseudomonas putida KT2440 (DSM 6125), Pseudomonas fluorescens (DSM 50090), and Rhodococcus opacus (DSM 1069) were purchased from Deutsche Sammlung von Mikroorganismen and Zellkulturen (Braunschweig, Germany). Sphingobium sp. SYK-6 (JCM 17495) was purchased from the Japan Collection of Microorganisms (Tsukuba, Japan). M9 mineral medium was used for all the plate and liquid culture experiments. The medium consisted of the following buffer salts (per $\mathrm{L}): 6 \mathrm{~g}$ of $\mathrm{Na}_{2} \mathrm{HPO}_{4}, 3 \mathrm{~g}$ of $\mathrm{KH}_{2} \mathrm{PO}_{4}, 1 \mathrm{~g}$ of $\mathrm{NH}_{4} \mathrm{Cl}, 0.5 \mathrm{~g}$ of $\mathrm{NaCl}, 2 \mathrm{mM}$ $\mathrm{MgSO}_{4}, 100 \mu \mathrm{M} \mathrm{CaCl}_{2}$, and $10 \mathrm{~mL}$ of trace element mixture. ${ }^{43}$ Sterile/ aseptic conditions were maintained throughout the cultivations. LB or oxidatively depolymerized LB was used as the sole carbon source at a concentration of $2-10 \mathrm{~g} / \mathrm{L}$. Before being added to the culture media, the substrates were acidified (if necessary) to $\mathrm{pH} \approx 9$ using sulfuric acid and were sterile filtered. The initial $\mathrm{pH}$ of cultivation media was 7 . All chemicals and reagents were of analytical grade and were used as received without further purification, unless otherwise stated.

Oxidative Depolymerization of LB. The oxidative depolymerization reactions were conducted in a $100 \mathrm{~mL}$ mechanically stirred Parr reactor equipped with a 4843 PID temperature controller (Parr Instruments Company, Moline, Illinois, USA). In a typical run, the reactor was loaded with $30 \mathrm{~mL}$ of $0.2 \mathrm{M} \mathrm{NaOH}$ aqueous solution (deionized water) and $600 \mathrm{mg}$ of LB substrate. The reactor was purged (three times) and pressurized with pure $\mathrm{O}_{2}$ to the target pressure and then heated to the desired reaction temperature $\left( \pm 3^{\circ} \mathrm{C}\right)$ while stirring $(500 \mathrm{rpm})$ and was maintained at this temperature for a reaction time of $30 \mathrm{~min}$. The heating time was $\sim 30-40 \mathrm{~min}$, depending on the reaction temperature. A matrix of nine experiments with various combinations of reaction temperature $\left(120-200{ }^{\circ} \mathrm{C}\right)$ and $\mathrm{O}_{2}$ partial pressure $(3-15$ bar) was investigated. After the desired reaction time, the reactor was rapidly quenched in an ice bath and depressurized at room temperature (cooling time $\leq 5 \mathrm{~min}$ ). The liquid products were finally collected for analysis and bacterial screenings.

To produce sufficient substrate for further microbial conversion experiments, upscaled oxidative depolymerization was performed using a similar method to that described above, with a $300 \mathrm{~mL}$ mechanically stirred Parr reactor equipped with a 4848 PID controller (featuring autotuning capability for precise temperature/pressure control and minimum overshoot). The reactor was loaded with $100 \mathrm{~mL}$ of $\mathrm{NaOH}$ aqueous solution ( $0.2 \mathrm{M}$; deionized water) and $2 \mathrm{~g}$ of $\mathrm{LB}$ substrate. The selected reaction conditions were $160^{\circ} \mathrm{C}\left( \pm 2^{\circ} \mathrm{C}\right), 3 \mathrm{bar} \mathrm{O}_{2}$, and $30 \mathrm{~min}$ reaction time under stirring $(500 \mathrm{rpm})$. The product is henceforth denoted ODLB. 
Biochemical Conversion of ODLB. Glycerol stocks (at $-80{ }^{\circ} \mathrm{C}$ ) containing the bacteria were streaked on nutrient-rich medium plates and incubated at $30{ }^{\circ} \mathrm{C}$ for $24 \mathrm{~h}$. M9 medium plates (with $1.5 \%$ agar), supplemented with $2 \mathrm{~g} / \mathrm{L}$ lignin, were then inoculated with a single colony from the nutrient-rich medium plates and incubated at $30^{\circ} \mathrm{C}$ for 7 days. All plate experiments were carried out in duplicate. The plates were regularly checked, and growth was documented by visual inspection.

Liquid culture experiments were carried out in $250 \mathrm{~mL}$ shake flasks containing $50 \mathrm{~mL}$ of culture media. M9 media with $10 \mathrm{~g} / \mathrm{L}$ glucose were used for precultures of $P$. putida, P. fluorescens, and $R$. opacus. Sphingobium sp. SYK-6 was precultured in Trypticase soy broth supplemented with yeast extract. All precultures were inoculated from a single colony from the respective rich-media plates and incubated overnight at $30{ }^{\circ} \mathrm{C}$ with orbital shaking $(180 \mathrm{rpm})$. Cells from the precultures were then washed with saline and subsequently used to inoculate flasks containing a sufficient amount of lignin to achieve an initial optical density of $\sim 4$. All shake flask experiments were performed in duplicate. Samples were withdrawn at regular intervals to monitor growth, changes in molecular weight, and the consumption of aromatic monomers. Biomass growth was determined by measuring the optical density at $620 \mathrm{~nm}\left(\mathrm{OD}_{620}\right)$. The samples were diluted with saline when required to ensure that the optical density remained in the linear range of $0.03-0.3$. As the color of lignin is dark, the respective culture supernatants were used as blanks prior to biomass measurements. The cells were then removed by centrifugation ( $3 \mathrm{~min}$ at $12300 \mathrm{~g}$ ), and the supernatants were stored at $-20^{\circ} \mathrm{C}$ for chemical analysis.

Characterization and Product Analysis. Size exclusion chromatography (SEC) was used to determine the molecular weight distribution (MWD), the weight-average molecular weight $\left(M_{w}\right)$, and the number-average molecular weight $\left(M_{n}\right)$ of LB and the ODLB products. The SEC system consisted of an AZURA high-performance liquid chromatography (HPLC) setup (Knauer, Berlin, Germany) with UV (UVD 2.1L) and RI (RID 2.1L) detectors, and a P 6.1L pump. Samples were injected with a Smartline Autosampler 3950, and the system was controlled, and peak evaluations were managed, using ClarityChrom 6.1.0 software. Two Superdex 10/300 GL columns, Peptide and 200 Increase (GE Healthcare Bio-Sciences AB, Uppsala, Sweden) were used to ensure high resolution over a large range of molecular weights (one column was used at a time). Analysis was performed at ambient temperature, under isocratic conditions, with a linear velocity of $23 \mathrm{~cm} / \mathrm{h}$. Calibration was carried out using nine different sodium polystyrene sulfonate standards, with molecular weights in the range of $200 \mathrm{Da}$ to $150 \mathrm{kDa}$. Each sample was diluted with $0.1 \mathrm{M} \mathrm{NaOH}$ to a concentration of $0.5-1 \mathrm{~g} / \mathrm{L}$ and filtered $(0.22$ $\mu \mathrm{m})$ to remove any suspended matter. The volume of filtered solution injected was $50 \mu \mathrm{L}$, and elution was performed for 100 min using an aqueous solution containing $0.1 \mathrm{M} \mathrm{NaOH}$.

Changes in the MWD of the samples after fermentation were analyzed using another SEC system, as described previously. ${ }^{44}$ This consisted of a Waters $600 \mathrm{E}$ chromatography system with an analytic column packed with $30 \mathrm{~cm}$ Superdex 30 and $30 \mathrm{~cm}$ Superdex 200 coupled to a Waters $2414 \mathrm{RI}$ detector and a Waters $486 \mathrm{UV}$ detector. The mobile phase used was $0.5 \mathrm{wt} \% \mathrm{NaOH}$ at a flow rate of $1 \mathrm{~mL} / \mathrm{min}$ (isocratic elution). The samples were centrifuged to remove the cells, and the supernatants were filtered and diluted (final concentration 0.5 $\mathrm{g} / \mathrm{L}$ ) before analysis. The injection volume was $500 \mu \mathrm{L}$, and the total run time for each sample was $180 \mathrm{~min}$. Lignin samples were compared before and after bioconversion by overlaying the SEC chromatograms obtained.

An ultraperformance liquid chromatography (UPLC) system (Waters Acquity) equipped with a photodiode array detector (Waters, Milford, MA, USA) was used for identification and quantification of the aromatic monomers in the lignin samples. The column used for separation was ethylene-bridged hybrid $\mathrm{C}_{18}$ with an internal diameter of $2.1 \mathrm{~mm}, 100 \mathrm{~mm}$ length, and $1.7 \mu \mathrm{m}$ particle size. The temperature of the column was maintained at $50{ }^{\circ} \mathrm{C}$. The mobile phase used was a mixture of $3 \%$ acetonitrile, $96.5 \%$ water, $0.5 \%$ acetic acid (fraction A), and $86.5 \%$ acetonitrile, $13 \%$ water, $0.5 \%$ acetic acid (fraction $\mathrm{B}$ ). The lignin samples were diluted with mobile phase (fraction A) to a final concentration of $0.5 \mathrm{~g} / \mathrm{L}$, and a volume of $2.5 \mu \mathrm{L}$ was injected. Gradient elution at a flow rate of $0.6 \mathrm{~mL} / \mathrm{min}$ was used for analysis. The method started with $100 \%$ A, decreased to $90 \%$ A over 5 min, held at $90 \%$ A for 2 min, and decreased to $25 \%$ A over $4.5 \mathrm{~min}$. After each sample was analyzed, the column was washed with $100 \% \mathrm{~B}$ for $5 \mathrm{~min}$ and then equilibrated with 100\% A for $5 \mathrm{~min}$. An Acquity UPLC Console was used to control the system, and Empower 3 was used to process the data. The compounds were identified by comparing the retention time and UV spectra (if necessary) with the corresponding standards. Peaks were quantified using the area under the curve against their respective calibration standards. The yields of aromatic monomers (in \%) were calculated based on the initial weight of lignin (estimated analysis deviation $\pm 5 \%)$.

A Waters Acquity HPLC system equipped with a UV and RI detector (Water, Milford, MA, USA) was used for the identification and quantification of nonaromatic acids. The column used for separation was an Aminex HPX-87H, at a temperature of $60^{\circ} \mathrm{C}$. The mobile phase was $5 \mathrm{mM} \mathrm{H}_{2} \mathrm{SO}_{4}$ at a flow rate of $0.6 \mathrm{~mL} / \mathrm{min}$ (isocratic elution). The sample injection volume was $20 \mu \mathrm{L}$, and the total run time for each sample was $50 \mathrm{~min}$. The data were reviewed and processed using Empower 3 software, and the compounds were identified by comparing the retention time with the respective standards. Peaks were quantified using the area under the curve against their respective calibration standards. The yields of nonaromatic acids (in \%) were calculated based on the initial weight of lignin (estimated analysis deviation $\pm 5 \%$ ).

Nuclear magnetic resonance (NMR) spectroscopy was used to analyze samples of the LB substrate and ODLB product by mixing 100 $\mathrm{mg}$ of the substrate or product with $600 \mu \mathrm{L}$ of DMSO- $d_{6}$ (SigmaAldrich, $99.9 \% \mathrm{D}$ ) and transferring the resultant samples to $5 \mathrm{~mm}$ NMR sample tubes. Two-dimensional ${ }^{1} \mathrm{H}-{ }^{13} \mathrm{C}$ correlation spectra of the substrate and product mixtures were recorded at $50{ }^{\circ} \mathrm{C}$ on a Bruker Avance III $800 \mathrm{MHz}$ spectrometer equipped with a TCI CryoProbe. The ${ }^{1} \mathrm{H}-{ }^{13} \mathrm{C}$ heteronuclear multiple-bond correlation (HMBC) spectra had a carrier offset of $110 \mathrm{ppm}$ and a spectral width in the ${ }^{13} \mathrm{C}$ dimension of $220 \mathrm{ppm}$. These ${ }^{1} \mathrm{H}-{ }^{13} \mathrm{C}$ HMBC spectra were recorded as data matrices of $2048 \times 128$ complex data points sampling the NMR signal for 197 and $2.9 \mathrm{~ms}$ in the ${ }^{1} \mathrm{H}$ and ${ }^{13} \mathrm{C}$ dimensions, respectively. An interscan recycle delay of $1.5 \mathrm{~s}$ and the accumulation of 128 scans per increment were employed, resulting in an analysis time of $16.5 \mathrm{~h}$ per $\mathrm{HMBC}$ spectrum. ${ }^{1} \mathrm{H}-{ }^{13} \mathrm{C}$ heteronuclear single-quantum correlation (HSQC) spectra with a carrier offset of $90 \mathrm{ppm}$ and a spectral width in the ${ }^{13} \mathrm{C}$ dimension of $180 \mathrm{ppm}$ were recorded as data matrices of $1024 \times 160$ complex data points sampling the NMR signals for 106 and $4.4 \mathrm{~ms}$ in the ${ }^{1} \mathrm{H}$ and ${ }^{13} \mathrm{C}$ dimensions, respectively. An interscan recycle delay of $1.5 \mathrm{~s}$ and the accumulation of 32 scans per increment were used, which resulted in an analysis time of $4.5 \mathrm{~h}$ per HSQC spectrum. All spectra were processed with extensive zero filling in both dimensions with Topspin 3.5.

High-resolution scanning electron microscopy (SEM) was used to visualize the morphologies of the lignin samples using an FEI Quanta $200 \mathrm{~F}$ microscope. The instrument was operated in low-vacuum mode to obtain charge contrast imaging data using a large field detector. Before measurements, the samples were gold coated using a current of $20 \mathrm{~mA}$ and $10 \mathrm{~s}$ sputter time (Quorum Q150T ES, Quorum Technologies Ltd., Laughton, UK) in order to minimize charging effects. Images were recorded at a low accelerating voltage $(3 \mathrm{kV})$, with a spot size of 3.0, and magnification of 10000 times.

Nitrogen adsorption-desorption isotherms were measured on an ASAP 2020 Micromeritics instrument (Norcross, GA, USA) to examine the surface areas and porous structures of the lignin samples. The samples were degassed at $110^{\circ} \mathrm{C}$ under high vacuum for $4 \mathrm{~h}$ prior to measurements. The Brunauer-Emmet-Teller (BET) and BarrettJoyner-Halenda methods ${ }^{45,46}$ were applied in the analysis to obtain the surface area (estimated deviation $\pm 0.2 \mathrm{~m}^{2} / \mathrm{g}$ ) and pore volume (estimated deviation $\pm 0.001 \mathrm{~cm}^{3} / \mathrm{g}$ ), respectively.

\section{RESULTS AND DISCUSSION}

Oxidative Depolymerization of LB - Effects on Molecular Weight Distribution. The molecular weight is a 
fundamental property of lignin and lignin-derived fractions, as it greatly impacts the recalcitrance and thus the valorization, of lignin. The most common characterization method used is SEC, ${ }^{47}$ which has proven reliable in determining the $M_{\mathrm{w}}$ and MWD of kraft lignin and its depolymerized fractions. ${ }^{17,27,33,48,49}$ SEC was used to evaluate the changes in molecular weight of lignin samples produced under different reaction conditions. The reaction numbers indicating the different conditions used are given in Table 1 , and the variation in molecular weight and

Table 1. Product Yields and $\mathrm{pH}$ Values from the Oxidative Depolymerization of LB Lignin

$\begin{array}{lcccc}\text { run }^{a} & \text { temperature }\left({ }^{\circ} \mathrm{C}\right) & P_{\mathrm{O}_{2}}(\text { bar }) & \text { monophenols + acids }(\%)^{b} & \mathrm{pH} \\ 1 & 120 & 3 & 5.2 & 13.1 \\ 2 & 120 & 9 & 6.3 & 12.6 \\ 3 & 120 & 15 & 9.4 & 10.1 \\ 4 & 160 & 3 & 8.3 & 12.3 \\ 5 & 160 & 9 & 10.5 & 8.3 \\ 6 & 160 & 15 & 10.4 & 7.6 \\ 7 & 200 & 3 & 6.8 & 12.0 \\ 8 & 200 & 9 & 13.1 & 8.4 \\ 9 & 200 & 15 & 14.2 & 7.0 \\ \text { blank } & - & - & 3.2 & 13.4\end{array}$

${ }^{a}$ Fixed reaction parameters: $20 \mathrm{~g} / \mathrm{L} \mathrm{LB}, 0.2 \mathrm{M} \mathrm{NaOH}$ aqueous solution, $30 \mathrm{~min} .{ }^{b}$ Basedon the total lignin substrate.

the relative mass abundance of corresponding oxygen-treated kraft lignin samples are shown in Figure 1. The SEC profiles of the substrate and product samples are shown in Figures S1-S2 in the Supporting Information.

The lignin starting material, LB (blank), exhibited a broad MWD with a dispersity index of 2.5 and an average molecular weight of about $48 \mathrm{kDa}$. A significant reduction in molecular size and narrower distributions were obtained after oxidative depolymerization (Figure 1a). For example, at a temperature of $120^{\circ} \mathrm{C}, M_{\mathrm{w}}$ values of $33.4,14.6$, and $8.8 \mathrm{kDa}$ were obtained at $\mathrm{O}_{2}$ pressures of 3,9 , and 15 bar, respectively (reactions $1-3$ ). Increasing the temperature to 160 and $200{ }^{\circ} \mathrm{C}$ resulted in further size reductions, with average $M_{\mathrm{w}}$ values of $6.4,4.4$, and $4.2 \mathrm{kDa}$ (reactions 4-6), and 3.3, 2.4, and $2.5 \mathrm{kDa}$ (reactions 7-9) at analogous $\mathrm{O}_{2}$ pressures. It is worth noting that, at the higher reaction temperatures, only a negligible effect on $M_{\mathrm{w}}$ was seen for $P_{\mathrm{O}_{2}}>9 \mathrm{bar}$, suggesting that the reaction was not limited by the gas accessibility under such conditions. The lowest dispersity index $(\sim 1.3)$ was also obtained following the harshest reaction conditions, indicating that high temperature and $\mathrm{O}_{2}$ pressure favored lignin breakdown into low molecular weight products.

A further illustration of the effects of the reaction conditions on the molecular size distribution and relative mass abundance is given in Figure 1b. Approximately half of the untreated LB lignin consisted of macromolecules with $M_{\mathrm{w}}>10 \mathrm{kDa}$, while the low molecular weight portion $(<1 \mathrm{kDa})$ represented less than $1 \%$ of the total abundance. When the reactions were performed at higher temperatures $\left(160-200{ }^{\circ} \mathrm{C}\right)$, a substantial shift in mass distribution was seen toward smaller lignin fragments. For instance, the fraction of higher oligomers $(1-3 \mathrm{kDa})$ increased gradually from 49 to $75 \%$ (reactions $4-9$ ), compared to the blank sample (19\%). Similarly, the portion rich in phenolic monomers, dimers, and trimers $(<1 \mathrm{kDa})$ increased to $4-12 \%$, confirming that both pressurized oxygen and higher temperature were needed to effectively depolymerize the LB lignin into low molecular weight products. Importantly, the abundance of high molecular weight fractions $(>10 \mathrm{kDa})$ was generally below $5 \%$ under these conditions, and none were found after reactions at $200{ }^{\circ} \mathrm{C}$ (reactions 7-9).

Oxidative Depolymerization of LB - Effects on Monomer Formation. Product distribution and yields resulting from lignin oxidative depolymerization are known to vary depending on the lignin source, ${ }^{37,50}$ operating conditions, ${ }^{51,52}$ and even the kind of pretreatment prior to oxidation. ${ }^{53}$ All product mixtures from oxidative depolymerization reactions in the present work were subjected to liquid chromatographic analysis to identify and quantify the phenolic monomers and carboxylic acids produced (Figure 2). The $\mathrm{pH}$ values of the mixtures were also determined to complement the characterization of the samples produced under different treatment conditions (Table 1).

The main aromatic monomeric compounds identified in the oxygen-treated samples were vanillin, vanillic acid, guaiacol, and acetovanillone (Figure 2a); the highest total yield of $3.2 \mathrm{wt} \%$ being observed after treatment at $160^{\circ} \mathrm{C}$ and 3 bar $\mathrm{O}_{2}$ (reaction 4). The higher yields obtained for vanillin and vanillic acid than in the blank sample (up to 5-fold increase), confirmed that oxygen promoted their formation. ${ }^{54}$ The yields obtained are in agreement with those reported by Singh and co-workers (3-5 wt \%) upon depolymerizing kraft lignin with alkaline hydrogen peroxide for further bioconversion. ${ }^{55}$ The amount of guaiacol produced also increased with increasing depolymerization temperature. Conversely, at fixed temperature, the guaiacol fraction decreased with increasing $\mathrm{O}_{2}$ pressure, suggesting that oxygen probably converted the guaiacol formed into either its corresponding aromatic aldehydes ${ }^{56}$ or predominantly carboxylic acids via ring opening. ${ }^{57}$

Formic and acetic acids, together with minor amounts of succinic acid ( $<0.5 \mathrm{wt} \%)$, were the predominant organic acids found in the depolymerized samples (4-13 wt \%, Figure $2 b$ ). The formation of carboxylic acids was especially pronounced at high temperature and $\mathrm{O}_{2}$ pressure, probably due to the oxidation of the aromatics under severe conditions, as mentioned above. This finding is consistent with the reaction being consecutive, such that the nonaromatic carboxylic acids are formed as breakdown products from the monophenol type compounds. Consecutive breakdown is supported by the positive effect of introducing additional $\mathrm{O}_{2}$ on monomeric aromatics at the lowest temperature $\left(120{ }^{\circ} \mathrm{C}\right)$ as opposed to the effect at higher temperatures with higher reaction rates $\left(\geq 160^{\circ} \mathrm{C}\right)$. A high ratio of organic acids to monoaromatic products was likewise reported by Lyu et $\mathrm{al.}^{28}$ in oxidative cracking of ammoniaextracted lignin from corn stover at high temperatures and oxygen pressures. Furthermore, Schutyser et al. ${ }^{29}$ found that vanillin could be further oxidized to nonaromatic carboxylic acids during alkaline aerobic oxidation, resulting predominantly in formic, malonic, and acetic acids, in line with the results of the present study. Notably, the formation of carboxylic acids lowered the $\mathrm{pH}$ of the depolymerized product mixtures from the initial $\mathrm{pH}$ of the untreated LB sample (13.4). Interestingly, almost neutral $\mathrm{pH}$ values (7.6 and 7.0) were observed in the product solutions after reactions at $15 \mathrm{bar}_{2}$ and temperatures of 160 and $200{ }^{\circ} \mathrm{C}$, respectively (reactions 6 and 9). This is an important observation, as near-neutral $\mathrm{pH}$ conditions are preferable for bacterial cultivation. In addition, a reduction in the $\mathrm{pH}$ of the product mixtures due to the oxygen treatment led to an increase in the level of soluble lignin components, thus enabling bioconversion at higher concentrations. 

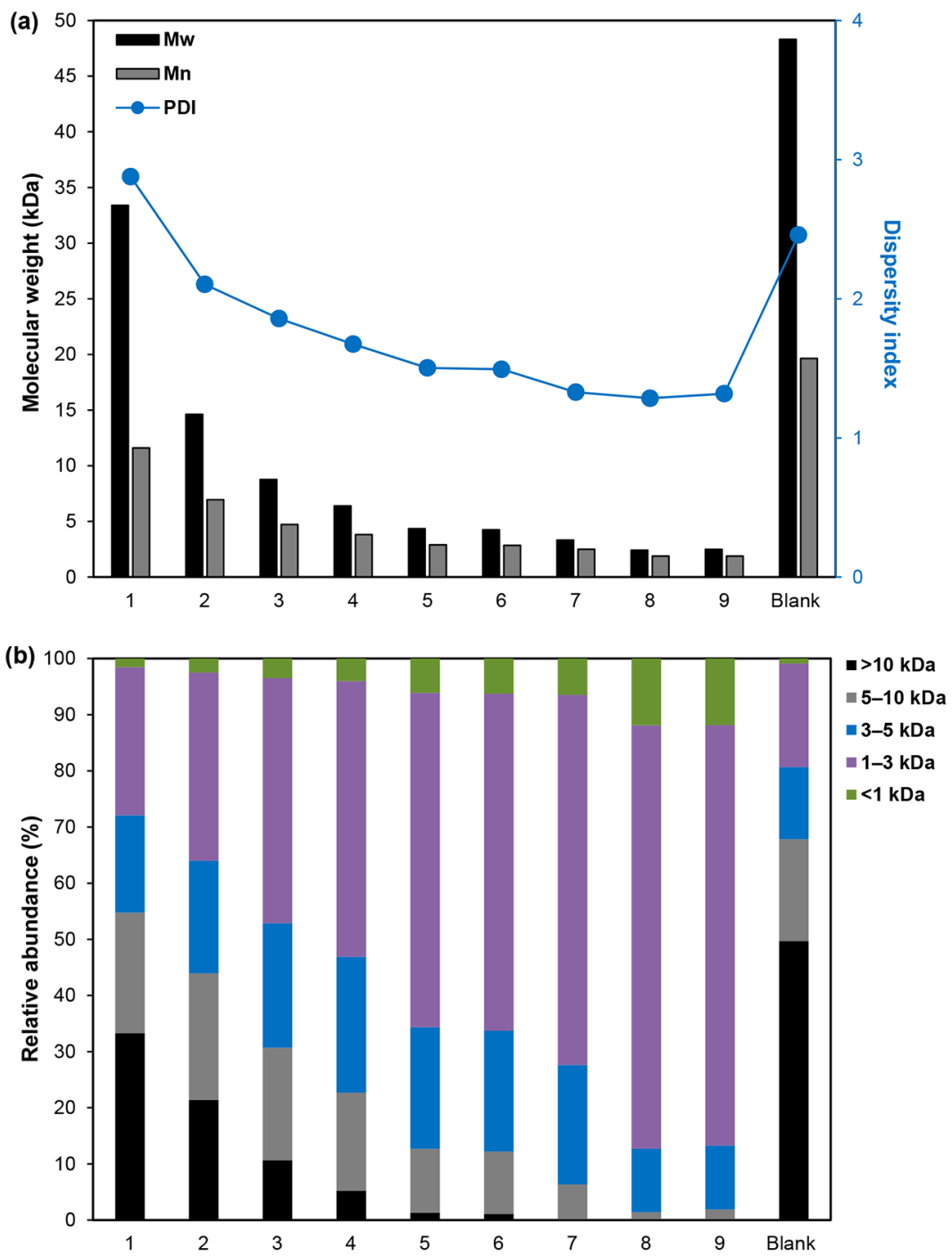

Figure 1. Molecular weight distribution and dispersity index (a) and relative mass abundance (b) for different depolymerized lignin samples. $M_{\mathrm{w}}$ is the weight-average molecular weight, $M_{\mathrm{n}}$ the number-average molecular weight, and PDI is the dispersity index. The reaction number according to Table 1 is given on the abscissa.

Overall, depolymerization of $\mathrm{LB}$ at $160{ }^{\circ} \mathrm{C}$ and 3 bar $\mathrm{O}_{2}$ pressure (reaction 4) provided the most favorable product mixture, with a high yield of aromatic monomers (3.2 wt \%) and a rather low content of highly oxidized compounds (i.e., carboxylic acids). This sample was thus deemed interesting for detailed chemical analysis using NMR, SEM, and BET, and for use in microbial liquid cultivation experiments. Hence, the reactor was scaled up to prepare a larger batch of the product under these conditions.

Characterization of ODLB. Heteronuclear NMR analysis at a high magnetic field was used to reveal structural variations between the native LB and ODLB lignin samples and to identify functional groups and molecular species in the product material. Figure 3 shows the two-dimensional ${ }^{1} \mathrm{H}-{ }^{13} \mathrm{C}$ HMBC NMR spectra obtained from the initial substrate and depolymerized product.

The presence of aromatic aldehydes, ketones, and carboxylic acids detected by UPLC/HPLC analysis was confirmed by $2 \mathrm{D}$ HMBC NMR. This method enabled visualization of such functional groups and demonstrated the changes between LB (Figure 3a) and ODLB (Figure 3b), especially regarding aliphatic and aromatic aldehydes, ketones, and acids $\left(\delta^{13} \mathrm{C} \sim\right.$ $170-215 \mathrm{ppm})$. The functional groups and molecules identified included, among others, aromatic aldehydes $\left(\alpha\right.$-aldehydes, $\delta^{13} \mathrm{C}$ $190.5 \mathrm{ppm})$, aromatic $\alpha$-ketones $\left(\delta^{13} \mathrm{C} 194.5-198.4 \mathrm{ppm}\right.$, with lower values indicative of an aromatic and an ether group adjacent to the keto group and higher values indicative of a rather short-chain substituent ketone), aromatic acetyl esters $\left(\delta^{13} \mathrm{C} 169.7 \mathrm{ppm}\right)$, aromatics with aliphatic functionalization (and $\mathrm{HMBC}$ correlations from $\delta^{1} \mathrm{H} 2.4 \mathrm{ppm}$ to aromatic carbon atoms), intact aromatic methyl ether signals, aliphatic acids including acetate, formate, lactate, and longer hydroxy acids, as well as aliphatic ketones and $\alpha$-keto acids $\left(\delta^{13} \mathrm{C} 177.6\right.$ and 203.9 ppm).

The structural motifs in the LB and ODLB samples were also compared using $2 \mathrm{D}{ }^{1} \mathrm{H}-{ }^{13} \mathrm{C}$ HSQC analysis (Figure S3). The spectra indicated variations between the materials, mostly in the interunit (oxygenated) aliphatic region. In addition, parts of the signals corresponding to nonoxygenated aliphatic moieties $\left(\delta^{13} \mathrm{C} / \delta^{1} \mathrm{H} 8.0-52.5 / 0.5-2.5 \mathrm{ppm}\right)$ disappeared after oxidative depolymerization. The HSQC data also showed a decrease in the methoxy resonance at $\delta^{13} \mathrm{C} / \delta^{1} \mathrm{H} \approx 56 / 3.7 \mathrm{ppm}$, whereas the 
(a)

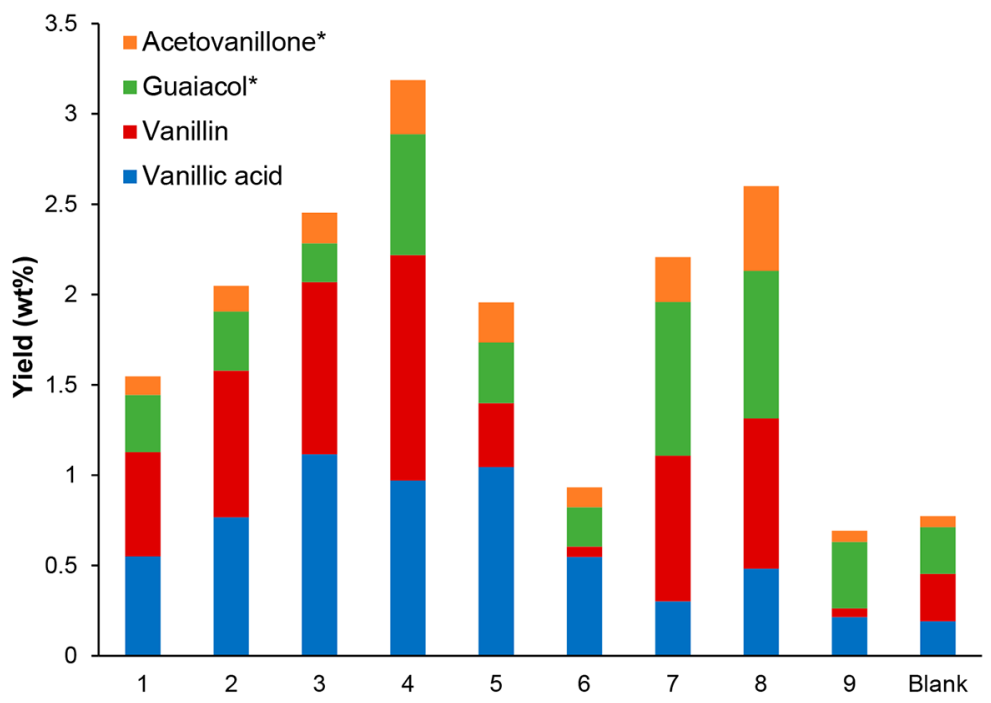

(b)

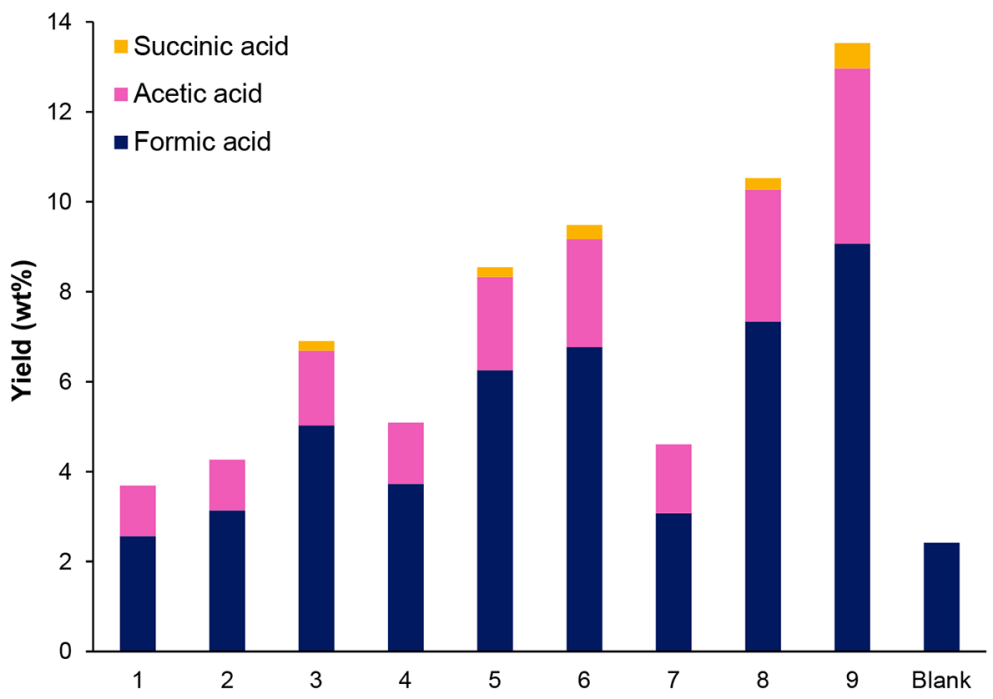

Figure 2. Impact of reaction temperature and oxygen pressure on the yield of (a) monophenols and (b) other carboxylic acids from the oxidative depolymerization of LB lignin. Reaction conditions: $20 \mathrm{~g} / \mathrm{L} \mathrm{LB}, 0.2 \mathrm{M} \mathrm{NaOH}$ aqueous solution, $30 \mathrm{~min}$. (*: Including coeluting compound, quantified with guaiacol and acetovanillone standards, respectively). The reaction number according to Table 1 is given on the abscissa.

aromatic chemical structures $\left(\delta^{13} \mathrm{C} / \delta^{1} \mathrm{H}\right.$ 105-140/6.0-8.0 $\mathrm{ppm})$ were apparently rather resistant to degradation under the treatment conditions applied. This stability indicates that it is possible to achieve depolymerization without oxidative breakage of the aromatic rings under suitably tuned conditions.

SEM characterization was carried out to gain insight into changes in the surface morphology of the LB after oxidative depolymerization. The SEM images obtained for LB and the ODLB lignin samples are shown in Figure 4.

The LB had a rather smooth surface emphasizing the high recalcitrance of the untreated lignin (Figure 4a). However, the surface of the ODLB product was considerably changed by the reaction, where the smooth surface was broken into smaller particles, accompanied by the appearance of needle-like structures and multilayer eroded parts (Figure 4b). Such morphological changes are consistent with the results reported by Wei and co-workers, ${ }^{42}$ and probably reduce the surface integrity of the native LB, making it more accessible to subsequent microbial conversion.

Nitrogen physisorption measurements were performed to provide quantitative estimates of the changes in surface area and pore structure of the lignin during the depolymerization process. The textural properties of the LB and ODLB lignin samples are summarized in Table 2. The $\mathrm{N}_{2}$ adsorption-desorption isotherms of the substrate and product samples are also shown in Figure S4 in the Supporting Information.

The original lignin had a specific surface area of $1.23 \mathrm{~m}^{2} / \mathrm{g}$ and a modest pore volume of $0.0015 \mathrm{~cm}^{3} / \mathrm{g}$. The calculated average pore size, assuming cylindrical pores, was $4.9 \mathrm{~nm}$. In comparison, the ODLB sample showed an almost 4-fold increase in specific surface area $\left(4.35 \mathrm{~m}^{2} / \mathrm{g}\right)$ together with an increase in pore size $(5.49 \mathrm{~nm})$ and pore volume $\left(0.0060 \mathrm{~cm}^{3} / \mathrm{g}\right)$, all of which are consistent with the structural interpretation of the SEM images discussed above.

The comparison of textural parameters resulting from the pretreatment of woody biomass by BET analysis has been shown to be useful. ${ }^{58}$ Although the mechanisms for the enzymatic degradation of cellulose and lignin differ, the fact that the ODLB sample had a higher surface area and pore size may allow easier access of enzymes and reactive mediators, which can facilitate further microbial lignin conversion. 


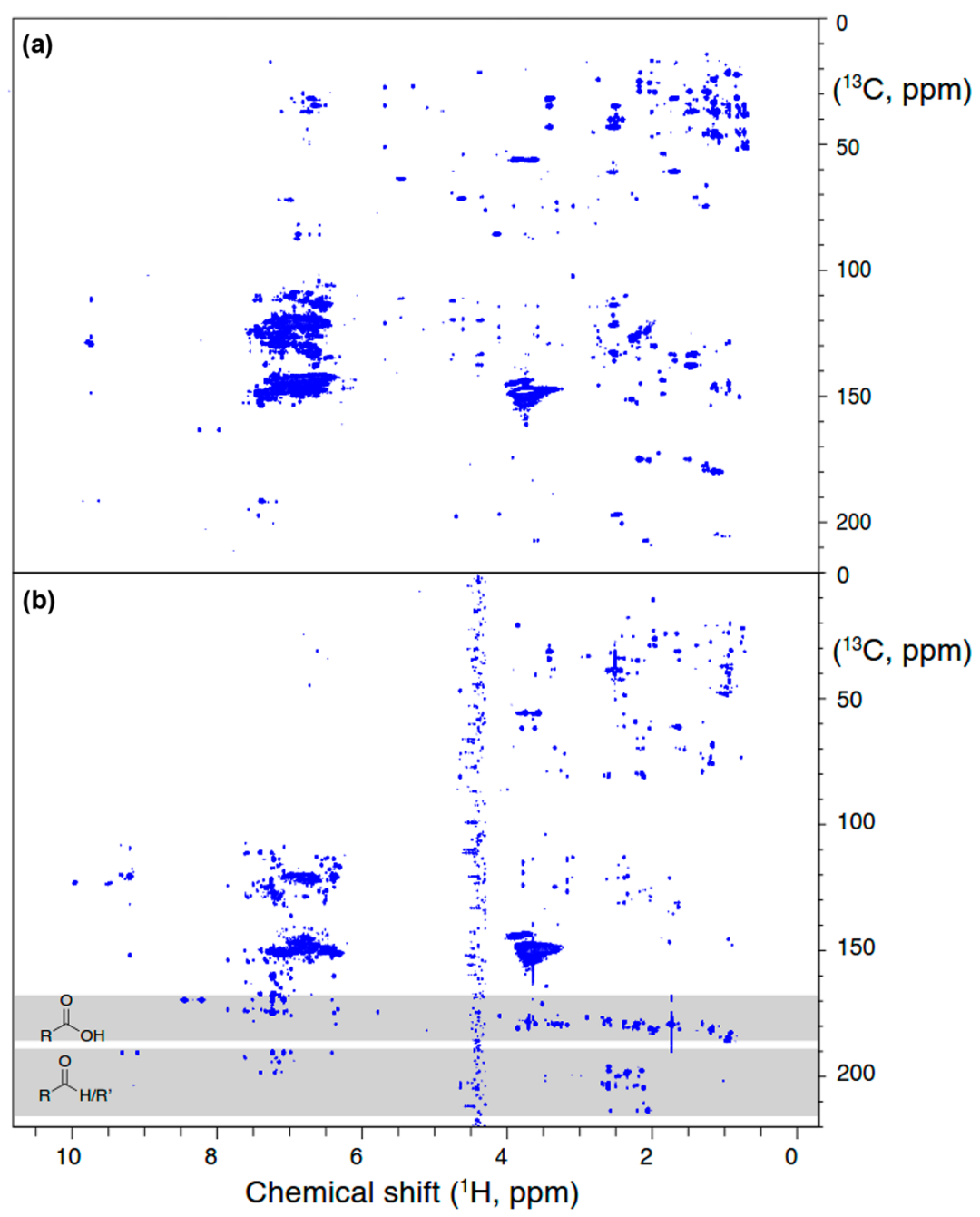

Figure 3. ${ }^{1} \mathrm{H}-{ }^{13} \mathrm{C} \mathrm{HMBC}$ NMR spectra of (a) LB and (b) ODLB lignin samples. The increased presence of aliphatic and aromatic aldehydes, ketones, and carboxylic acids is indicated by a highlight of characteristic spectral regions in panel b. Reaction conditions: $20 \mathrm{~g} / \mathrm{L} \mathrm{LB}, 0.2 \mathrm{M} \mathrm{NaOH}$ aqueous solution, $160{ }^{\circ} \mathrm{C}, 3$ bar $\mathrm{O}_{2}, 30 \mathrm{~min}$.
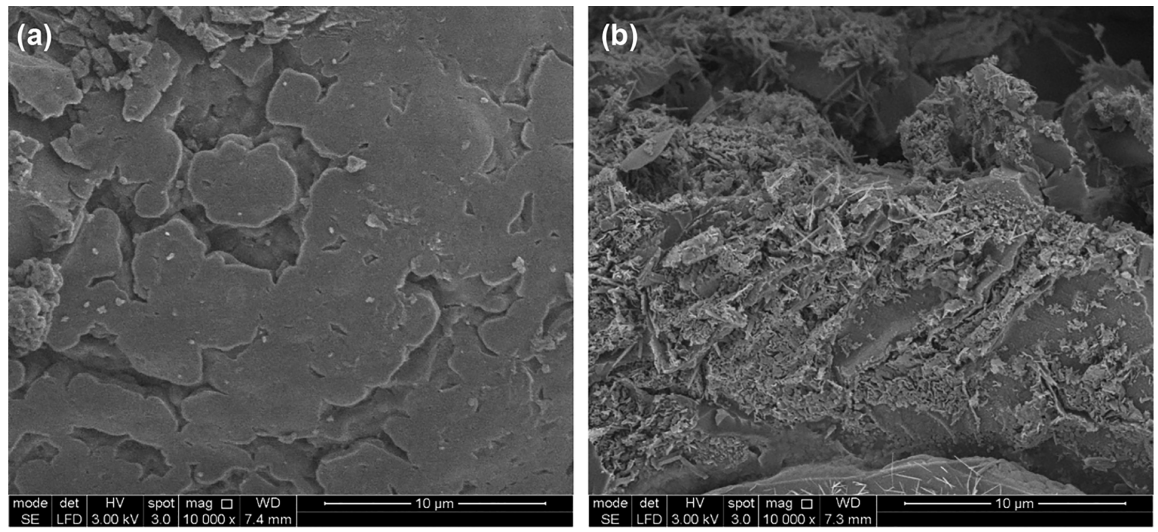

Figure 4. SEM images of (a) LB and (b) ODLB lignin samples. Reaction conditions: $20 \mathrm{~g} / \mathrm{L} \mathrm{LB}, 0.2 \mathrm{M} \mathrm{NaOH}$ aqueous solution, $160^{\circ} \mathrm{C}, 3$ bar $\mathrm{O}_{2}, 30$ min.

Bacterial Growth on Depolymerized LB. Microbial growth on the produced lignin samples was evaluated on M9 agar plates using LB and LB treated under different conditions (reactions 1-9 and blank, Table 1) as the sole source of carbon and energy. The bacterial strains Pseudomonas putida KT2440,
Pseudomonas fluorescens, Rhodococcus opacus, and Sphingobium sp. strain SYK-6 have previously been reported to metabolize similar lignin substrates or related lignin monomers. ${ }^{42,59}$ These experiments allowed us to determine whether any of the unknown compounds in the depolymerized products were toxic, 
Table 2. Textural Properties of Lignin Samples Calculated using BET Analysis

$\begin{array}{lccc}\text { sample } & \text { BET surface area }\left(\mathrm{m}^{2} / \mathrm{g}\right) & \text { pore size }(\mathrm{nm}) & \text { pore volume }\left(\mathrm{cm}^{3} / \mathrm{g}\right) \\ \text { LB } & 1.23 & 4.90 & 0.0015 \\ \text { ODLB }^{a} & 4.35 & 5.49 & 0.0060\end{array}$

${ }^{a}$ Reaction conditions: $20 \mathrm{~g} / \mathrm{L} \mathrm{LB}, 0.2 \mathrm{M} \mathrm{NaOH}$ aqueous solution, 160 ${ }^{\circ} \mathrm{C}, 3$ bar $\mathrm{O}_{2}, 30 \mathrm{~min}$.

in particular to microbial growth at the given concentrations. Both Pseudomonas species showed abundant growth on most of the treated lignin samples already after $120 \mathrm{~h}$ (data not shown), indicating that these strains could easily metabolize the compounds present. After 7 days of incubation, $R$. opacus and Sphingobium sp. SYK-6 were also able to grow on the agar plates, including those containing the untreated LB lignin (Table 3).

The results presented in Table 3 suggest that neither LB nor the depolymerized products obtained under different conditions was toxic to bacterial growth at the concentrations present. Less growth was seen on the untreated LB substrate than on the depolymerized lignin samples (Table 3), which is in line with the lower amount of readily available monomers for direct consumption in LB (Table 1; Figure 2). The reason for abundant growth on the substrates treated under harsh conditions (i.e., high temperature and oxygen pressure) may be the higher acid concentrations (up to $13.5 \%$, Figure $2 \mathrm{~b}$ ), as some of the organisms used in this study have previously demonstrated the ability to grow on similar acids. ${ }^{38,60}$

Shake Flask Experiments with ODLB. High-cell-density inoculations $(\mathrm{OD} \approx 3.5-4)$ were performed to assess the utilization of low molecular weight compounds in ODLB as carbon sources, as well as possible enzymatic effects on the molecular size of the lignin. All four organisms tested in the plate screening experiments were used for liquid cultivations in shake flasks, with a lignin concentration of $2 \mathrm{~g} / \mathrm{L}$ as the sole carbon source and incubation for about $150 \mathrm{~h}$.

After inoculation, a slight decrease in OD was observed for all organisms, after which P. putida KT2440, R. opacus, and Sphingobium sp. SYK-6 showed maintained OD throughout the cultivation (Figure 5). In the case of P.fluorescens, a decrease in OD (from 3.7 to 2.5 ) was seen during the first $45 \mathrm{~h}$, which was probably caused by the formation of cell aggregates, which could be seen by microscopic examination. This response of $P$. fluorescens has previously been reported and described as a reaction to toxic shock. ${ }^{22}$ In addition, the formation of a biofilm was observed at the air-liquid interface in the shake flasks for all organisms.

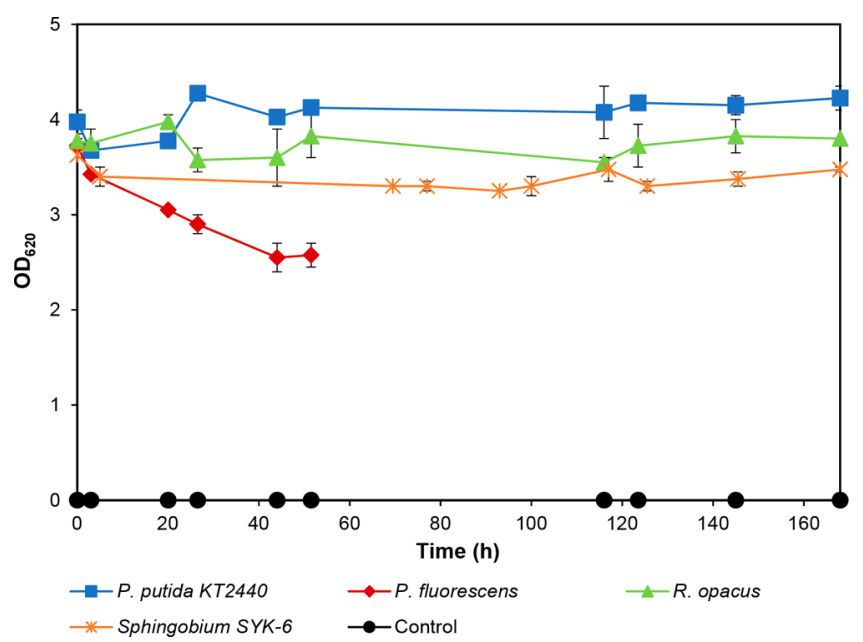

Figure 5. Cell density of bacterial species cultivated on $\mathrm{M} 9$ medium supplemented with $2 \mathrm{~g} / \mathrm{L}$ ODLB lignin $\left(160^{\circ} \mathrm{C}\right.$ and 3 bar $\left.\mathrm{O}_{2}\right)$ as the sole source of carbon and energy. Cultivations were performed in duplicate, and the data points represent the average, and the error bars the standard deviation.

Furthermore, P. putida KT2440 and Sphingobium sp. SYK-6 were cultivated in higher lignin concentrations $(10 \mathrm{~g} / \mathrm{L}$ ODLB $)$ together with lower initial cell densities $(\mathrm{OD}<0.01)$. The results showed a clear growth of these organisms on lignin with a maximum OD of around 0.45 (Figure S5). The consumption of monomers by the organisms was in agreement with the highcell-density experiments (detailed below).

The consumption of aromatic monomers by the bacterial strains was analyzed using UPLC. Both the Pseudomonas strains and Sphingobium sp. SYK-6 were able to convert vanillin to vanillic acid and eventually consume all the vanillic acid available and produced in less than $50 \mathrm{~h}$ (Figure 6). The conversion of toxic aldehydes, such as vanillin, to their respective acids has been described previously. ${ }^{61}$ In contrast, $R$. opacus converted vanillin to vanillyl alcohol as an intermediate, after which vanillin, vanillic acid, and vanillyl alcohol were completely consumed within $21 \mathrm{~h}$. The detoxification of vanillin to its corresponding alcohol has mostly been reported in yeast, but also in a few bacteria, such as Gluconacetobacter xylinus and Pseudomonas sp. isolate $9.1 .^{62-64}$ The accumulation of vanillyl alcohol instead of vanillic acid in $R$. opacus might be due to the poor expression of the gene encoding for the vanillin dehydrogenase enzyme. ${ }^{65}$

Table 3. Growth of Bacterial Strains on M9 Agar Plates with LB Lignin ( $2 \mathrm{~g} / \mathrm{L})$ Treated under Different Conditions ${ }^{a}$

\begin{tabular}{|c|c|c|c|c|c|c|c|c|c|c|c|c|c|c|c|c|c|c|c|c|}
\hline Temperature $\left({ }^{\circ} \mathrm{C}\right)$ & \multicolumn{6}{|c|}{120} & \multicolumn{6}{|c|}{160} & \multicolumn{6}{|c|}{200} & \multirow{2}{*}{\multicolumn{2}{|c|}{ Untreated }} \\
\hline Pressure $\mathrm{O}_{2}$ (bar) & \multicolumn{2}{|c|}{3} & \multicolumn{2}{|c|}{9} & \multicolumn{2}{|c|}{15} & \multicolumn{2}{|c|}{3} & \multicolumn{2}{|c|}{9} & \multicolumn{2}{|c|}{15} & \multicolumn{2}{|c|}{3} & \multicolumn{2}{|c|}{9} & \multicolumn{2}{|c|}{15} & & \\
\hline Organism & I & II & I & II & I & II & I & II & I & II & I & II & I & II & I & II & I & II & I & II \\
\hline P. putida $\mathrm{KT} 2440$ & +1 & + & ++ & + & ++ & ++ & ++ & ++ & +1 & ++ & +1 & ++ & ++ & ++ & ++ & ++ & ++ & ++ & + & + \\
\hline P. fluorescens & + & + & + & + & ++ & + & + & ++ & ++ & ++ & ++ & ++ & + & ++ & ++ & ++ & ++ & ++ & + & + \\
\hline R. opacus & + & + & + & + & + & + & + & + & ++ & + & + & + & - & - & + & + & ++ & ++ & + & + \\
\hline Sphingobium SYK-6 & + & + & ++ & + & ++ & ++ & + & + & + & + & ++ & + & ++ & + & + & ++ & + & + & + & + \\
\hline
\end{tabular}

${ }^{a_{T}}$ The plates were incubated at $30{ }^{\circ} \mathrm{C}$ for 7 days. Biological duplicates are indicated by I and II (++ abundant growth; + growth; - no growth). 


\section{P. putida KT2440}

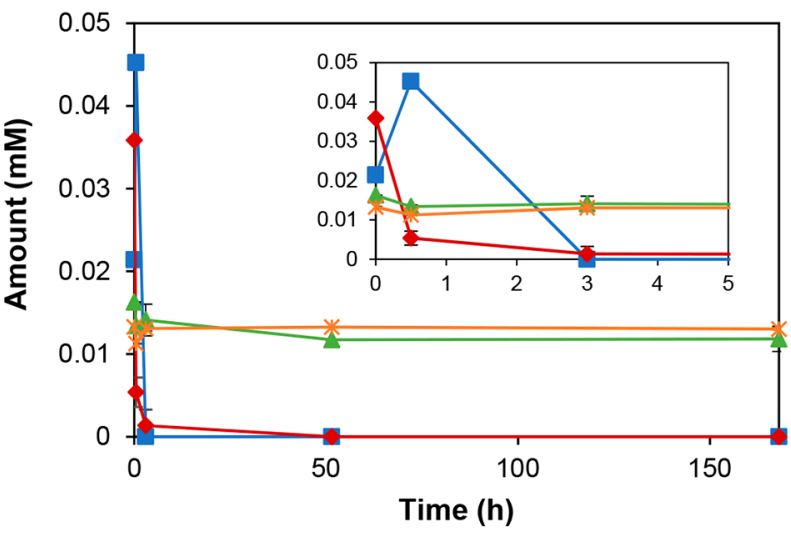

R. opacus

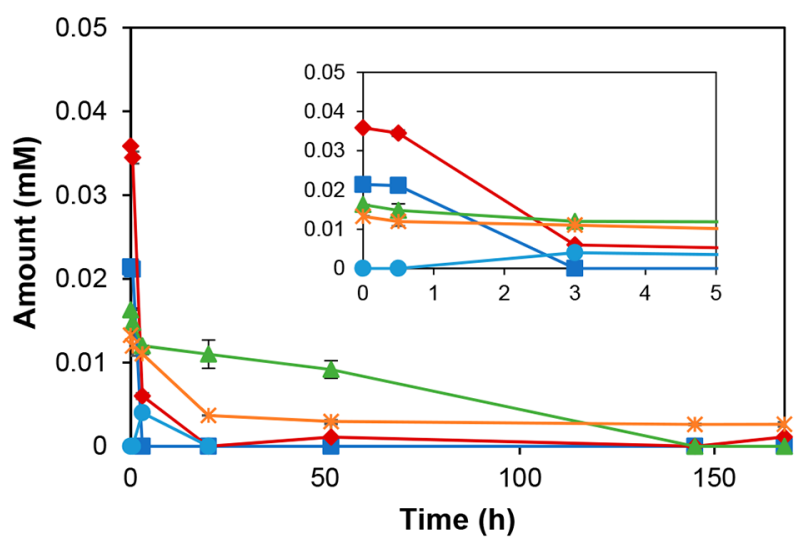

Vanillate

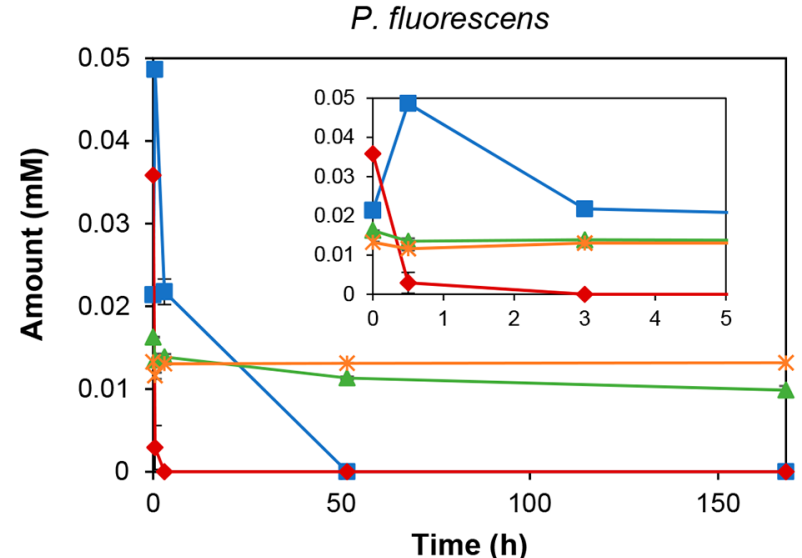

Sphingobium sp. SYK-6

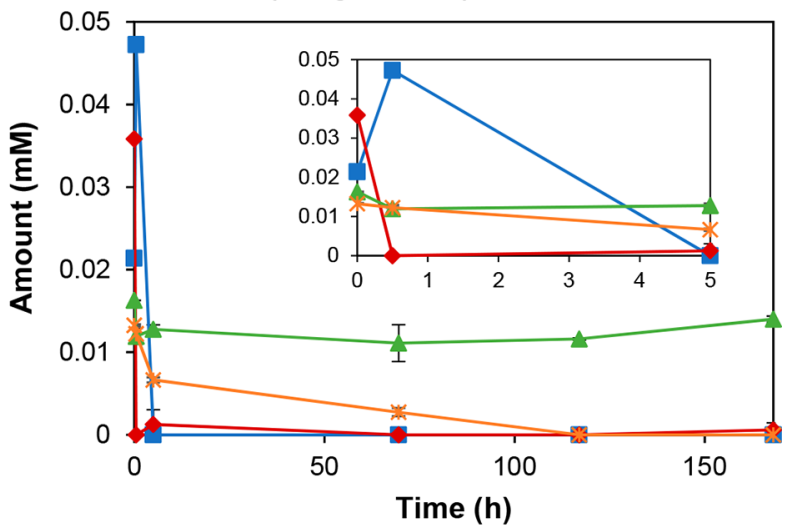

* Acetovanillone* $\quad-$ - Vanillyl alcohol

Figure 6. Consumption of aromatic monomers in the high-cell-density cultivations on ODLB lignin $(2 \mathrm{~g} / \mathrm{L})$ as a function of time. $(*+$ coeluting substance, quantified using guaiacol and acetovanillone standards, respectively). The first $5 \mathrm{~h}$ are enlarged for better readability in the initial cultivation phases. Data points represent the average of the duplicate experiments and the error bars the standard deviation.

The UPLC peaks eluting at 4.7 and $5.0 \mathrm{~min}$ are believed to be guaiacol and acetovanillone, respectively, based on their retention times. However, the UV spectra of these compounds suggest that the peaks coelute with some other unidentified compounds. $R$. opacus was the only organism to consume guaiacol and its coeluting compound within $150 \mathrm{~h}$ (Figure 6). Besides $R$. opacus, a few Gram-positive bacteria have been reported to be able to grow on guaiacol as the sole carbon source. $^{66}$ The enzyme cytochrome P450 monooxygenase responsible for the demethylation of guaiacol to catechol has been described in both Gram-positive and Gram-negative bacteria, such as Rhodococcus rhodochrous, Amycolatopsis sp., and Moraxella sp. ${ }^{67-69}$ Neither the Pseudomonas strains nor Sphingobium sp. SYK-6 was able to assimilate guaiacol within 150 h (Figure 6). Although P. putida KT2440 has been reported to possess the pathway for catechol degradation, growth was not observed in this study. Sphingobium sp. SYK-6 has $\beta$-etherase genes that cleave the $\beta$-aryl ether linkages in lignin dimers to generate guaiacol, but the assimilation of guaiacol has not been reported. $^{99}$

Sphingobium sp. SYK-6 was the only organism able to metabolize acetovanillone and its coeluting compound in around $100 \mathrm{~h}$ (Figure 6). In a recent study, we found that $R$. opacus was unable to assimilate acetovanillone, ${ }^{41}$ which suggests that the coeluting compound was consumed within $20 \mathrm{~h}$ in this case, leaving the acetovanillone in the culture medium unconsumed for $150 \mathrm{~h}$ (Figure 6). The bioconversion of some compounds, such as ferulic acid and 4-vinyl guaiacol, to acetovanillone has been described in a few organisms, ${ }^{70}$ but the consumption of acetovanillone as the sole carbon source has not been reported. None of the Pseudomonas species included in the current study were able to assimilate acetovanillone in $150 \mathrm{~h}$ (Figure 6), despite the high cell density, which suggests the absence of the required enzymes.

SEC analysis was performed to assess changes in the dissolved higher molecular weight lignin fraction present in the substrate, caused by the action of extracellular enzymes, such as laccases and peroxidases. A noninoculated control flask was monitored to see if the changes in molecular weight were also observed in the absence of microbial action. On the basis of related work, ${ }^{41}$ it is suggested that the peaks at long retention times (around 105 and $94 \mathrm{~min}$ ) represented low molecular weight monomers or short oligomers, whereas the broad peak at $89 \mathrm{~min}$ represents larger lignin fractions (Figure 7).

After $70 \mathrm{~h}$, the monomer peaks disappeared in all cultivations, suggesting the consumption of most of the available monomers. At the end of cultivation $(168 \mathrm{~h})$, all organisms showed an increase in the intensity of the polymer peak, the highest absorption being measured for P. fluorescens (0.18). After $168 \mathrm{~h}$, there was also a slight increase in the polymer peak of the 

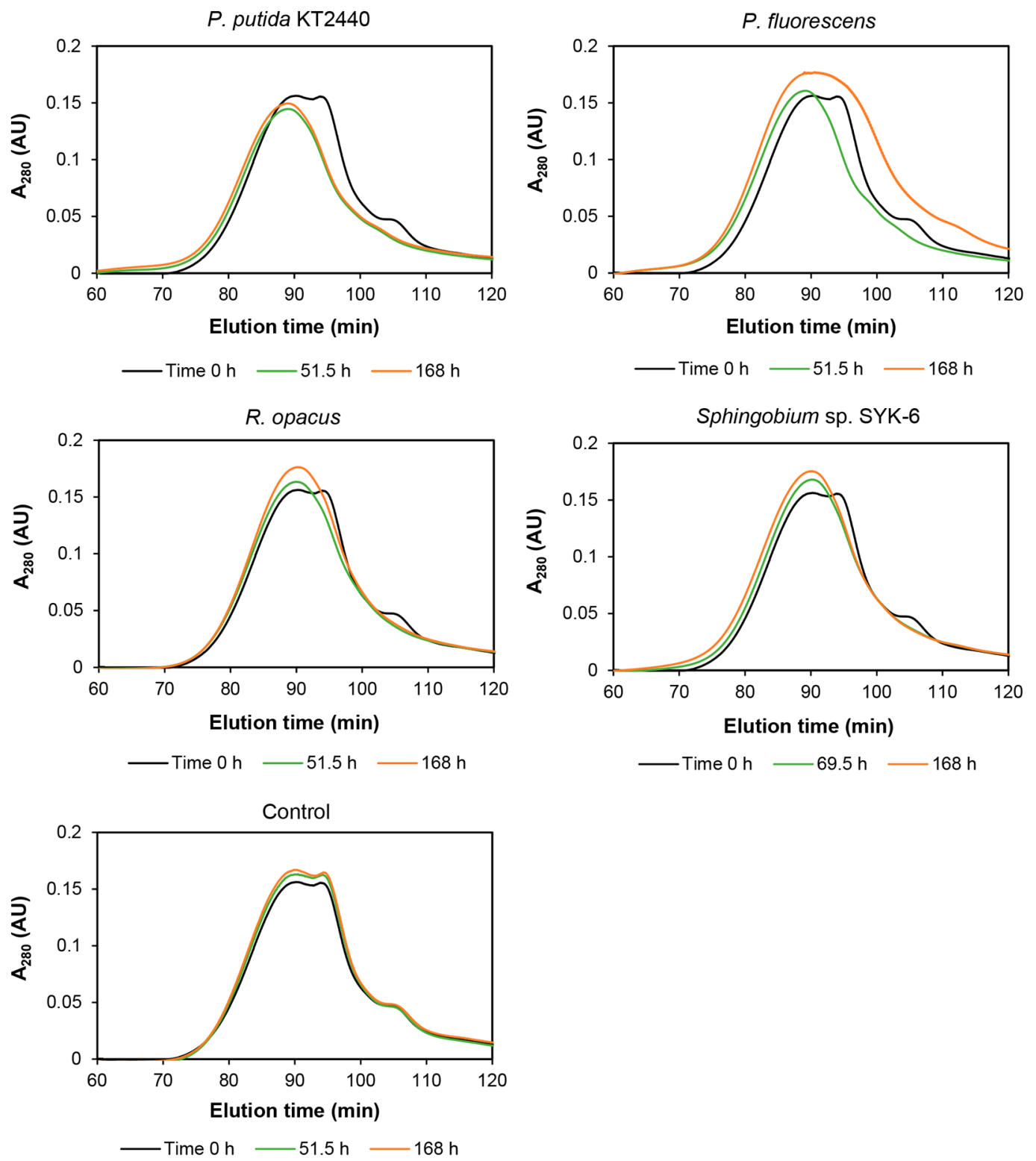

Figure 7. SEC chromatograms of samples from high-cell-density cultivations on $2 \mathrm{~g} / \mathrm{L}$ ODLB lignin $\left(160^{\circ} \mathrm{C}\right.$ and 3 bar $\left.\mathrm{O}_{2}\right)$ and from a noninoculated control. Results are shown for samples collected at 0, 51.5, and $168 \mathrm{~h} \mathrm{(P.} \mathrm{putida} \mathrm{KT2440,} \mathrm{P.} \mathrm{fluorescens,} \mathrm{R.} \mathrm{opacus,} \mathrm{and} \mathrm{control)} \mathrm{or} \mathrm{at} \mathrm{0,} \mathrm{69.5,} \mathrm{and} 168 \mathrm{~h}$ (Sphingobium sp. SYK-6). Elution time ( $\mathrm{min})$ and absorbance at $280 \mathrm{~nm}$ are indicated. AU, arbitrary units.

noninoculated control (Figure 7), which was probably due to the condensation of unstable lignin fragments. Apart from the increase in peak height, a peak shift/widening toward higher molecular weight was also observed in the inoculated flasks (except in the case of $R$. opacus), but not in the control flask (Figure 7). These observations suggest that repolymerization of polymeric lignin is stronger in the presence of bacterial species, which might be due to the secretion of extracellular enzymes. All the organisms included in this study have previously been reported to secrete extracellular lignin-degrading/polymerizing enzymes. ${ }^{2,71,72}$ The action of these enzymes in the polymerization or depolymerization of a particular substrate depends on various factors, such as the reaction temperature/time, the structure of the lignin, substrate loading, the presence of a mediator, and the origin of the enzyme.

In conclusion, the results presented in this study show that oxidative depolymerization of technical lignin, under rather mild operating conditions, can produce low molecular weight fractions that are amenable to microbial conversion. The work adds to the state of the art within lignin refining by including novel investigations on oxidation reaction parameters and multiple microbial species, thus allowing obtaining an approach that is more green and benign than previously reported. This approach can hopefully be broadly applied to enable the production of various bioproducts based on industrial kraft lignin streams. However, the depolymerization and fermentation conditions should be optimized to allow scalability and process/product development.

\section{ASSOCIATED CONTENT}

S Supporting Information

The Supporting Information is available free of charge on the ACS Publications website at DOI: 10.1021/acssuschemeng.9b01605. 
SEC chromatograms of the untreated LB substrate and the oxidatively depolymerized lignin products generated at different reaction conditions; $2 \mathrm{D}^{1} \mathrm{H}-{ }^{13} \mathrm{C} \mathrm{HSQC}$ NMR spectra showing aliphatic, interunit, and aromatic regions for the LB and the ODLB lignin samples as well as their $\mathrm{N}_{2}$ adsorption-desorption isotherms; growth curves for Pseudomonas putida KT2440 and Sphingobium sp. SYK6 with $10 \mathrm{~g} / \mathrm{L}$ ODLB (PDF)

\section{AUTHOR INFORMATION}

\section{Corresponding Author}

*E-mail: christian.hulteberg@chemeng.lth.se.

\section{ORCID}

Omar Y. Abdelaziz: 0000-0002-3530-3509

Sebastian Meier: 0000-0003-3761-3217

Anders Riisager: 0000-0002-7086-1143

Christian P. Hulteberg: 0000-0002-3502-5529

\section{Notes}

The authors declare no competing financial interest.

\section{ACKNOWLEDGMENTS}

This work was financed by the Swedish Foundation for Strategic Research (RBP14-0052). O.Y.A. acknowledges internal funding from Lund University and the Technical University of Denmark. We thank Anders Arkell, Arkell Innovations AB, for SEC measurements. The $800 \mathrm{MHz}$ NMR spectra were recorded using the spectrometer at the DTU NMR Center, supported by the Villum Foundation.

\section{REFERENCES}

(1) Zakzeski, J.; Bruijnincx, P. C. A.; Jongerius, A. L.; Weckhuysen, B. M. The Catalytic Valorization of Lignin for the Production of Renewable Chemicals. Chem. Rev. 2010, 110 (6), 3552-3599.

(2) Li, C.; Zhao, X.; Wang, A.; Huber, G. W.; Zhang, T. Catalytic Transformation of Lignin for the Production of Chemicals and Fuels. Chem. Rev. 2015, 115 (21), 11559-11624.

(3) Abdelaziz, O. Y.; Brink, D. P.; Prothmann, J.; Ravi, K.; Sun, M.; García-Hidalgo, J.; Sandahl, M.; Hulteberg, C. P.; Turner, C.; Lidén, G.; et al. Biological Valorization of Low Molecular Weight Lignin. Biotechnol. Adv. 2016, 34 (8), 1318-1346.

(4) Schutyser, W.; Renders, T.; Van den Bosch, S.; Koelewijn, S.-F.; Beckham, G. T.; Sels, B. F. Chemicals from Lignin: An Interplay of Lignocellulose Fractionation, Depolymerisation, and Upgrading. Chem. Soc. Rev. 2018, 47, 852-908.

(5) Ragauskas, A. J.; Beckham, G. T.; Biddy, M. J.; Chandra, R.; Chen, F.; Davis, M. F.; Davison, B. H.; Dixon, R. A.; Gilna, P.; Keller, M.; et al. Lignin Valorization: Improving Lignin Processing in the Biorefinery. Science 2014, 344 (6185), 1246843.

(6) Key, R. E.; Bozell, J. J. Progress toward Lignin Valorization via Selective Catalytic Technologies and the Tailoring of Biosynthetic Pathways. ACS Sustainable Chem. Eng. 2016, 4 (10), 5123-5135.

(7) Gillet, S.; Aguedo, M.; Petitjean, L.; Morais, A. R. C.; da Costa Lopes, A. M.; Łukasik, R. M.; Anastas, P. T. Lignin Transformations for High Value Applications: Towards Targeted Modifications Using Green Chemistry. Green Chem. 2017, 19 (18), 4200-4233.

(8) Moshkelani, M.; Marinova, M.; Perrier, M.; Paris, J. The Forest Biorefinery and Its Implementation in the Pulp and Paper Industry: Energy Overview. Appl. Therm. Eng. 2013, 50 (2), 1427-1436.

(9) Sjöström, E. Wood Chemistry: Fundamentals and Applications, 2nd ed., Academic Press, Inc.: San Diego, CA, 1993.

(10) Calvo-Flores, F. G.; Dobado, J. A.; Isac-García, J.; MartínMartínez, F. J. Lignin and Lignans as Renewable Raw Materials: Chemistry, Technology and Applications; John Wiley \& Sons, Ltd: Chichester, UK, 2015.
(11) Rinaldi, R.; Jastrzebski, R.; Clough, M. T.; Ralph, J.; Kennema, M.; Bruijnincx, P. C. A.; Weckhuysen, B. M. Paving the Way for Lignin Valorisation: Recent Advances in Bioengineering, Biorefining and Catalysis. Angew. Chem., Int. Ed. 2016, 55 (29), 8164-8215.

(12) Jönsson, J.; Pettersson, K.; Berntsson, T.; Harvey, S. Comparison of Options for Utilization of a Potential Steam Surplus at Kraft Pulp Mills-Economic Performance and CO2 Emissions. Int. J. Energy Res. 2013, 37 (9), 1017-1035.

(13) Tomani, P. The LignoBoost Process. Cellul. Chem. Technol. 2010, $44(1-3), 53-58$.

(14) Öhman, F.; Theliander, H.; Tomani, P.; Axegard, P. Method for Separating Lignin from Black Liquor. U.S. Patent 8,486,224, 2013.

(15) Hu, J.; Zhang, Q.; Lee, D.-J. Kraft Lignin Biorefinery: A Perspective. Bioresour. Technol. 2018, 247, 1181-1183.

(16) Bruijnincx, P. C. A.; Rinaldi, R.; Weckhuysen, B. M. Unlocking the Potential of a Sleeping Giant: Lignins as Sustainable Raw Materials for Renewable Fuels, Chemicals and Materials. Green Chem. 2015, 17 (11), 4860-4861.

(17) Aminzadeh, S.; Lauberts, M.; Dobele, G.; Ponomarenko, J.; Mattsson, T.; Lindström, M. E.; Sevastyanova, O. Membrane Filtration of Kraft Lignin: Structural Charactristics and Antioxidant Activity of the Low-Molecular-Weight Fraction. Ind. Crops Prod. 2018, 112, 200-209.

(18) Sun, Z.; Fridrich, B.; De Santi, A.; Elangovan, S.; Barta, K. Bright Side of Lignin Depolymerization: Toward New Platform Chemicals. Chem. Rev. 2018, 118 (2), 614-678.

(19) Pu, Y.; Hu, F.; Huang, F.; Ragauskas, A. J. Lignin Structural Alterations in Thermochemical Pretreatments with Limited Delignification. BioEnergy Res. 2015, 8 (3), 992-1003.

(20) Pandey, M. P.; Kim, C. S. Lignin Depolymerization and Conversion: A Review of Thermochemical Methods. Chem. Eng. Technol. 2011, 34 (1), 29-41.

(21) Gall, D. L.; Ralph, J.; Donohue, T. J.; Noguera, D. R. Biochemical Transformation of Lignin for Deriving Valued Commodities from Lignocellulose. Curr. Opin. Biotechnol. 2017, 45, 120-126.

(22) Salvachúa, D.; Karp, E. M.; Nimlos, C. T.; Vardon, D. R.; Beckham, G. T. Towards Lignin Consolidated Bioprocessing: Simultaneous Lignin Depolymerization and Product Generation by Bacteria. Green Chem. 2015, 17, 4951-4967.

(23) Zhao, C.; Xie, S.; Pu, Y.; Zhang, R.; Huang, F.; Ragauskas, A. J.; Yuan, J. S. Synergistic Enzymatic and Microbial Lignin Conversion. Green Chem. 2016, 18 (5), 1306-1312.

(24) Sturgeon, M. R.; Kim, S.; Lawrence, K.; Paton, R. S.; Chmely, S. C.; Nimlos, M.; Foust, T. D.; Beckham, G. T. A Mechanistic Investigation of Acid-Catalyzed Cleavage of Aryl-Ether Linkages: Implications for Lignin Depolymerization in Acidic Environments. ACS Sustainable Chem. Eng. 2014, 2 (3), 472-485.

(25) Katahira, R.; Mittal, A.; McKinney, K.; Chen, X.; Tucker, M. P.; Johnson, D. K.; Beckham, G. T. Base-Catalyzed Depolymerization of Biorefinery Lignins. ACS Sustainable Chem. Eng. 2016, 4 (3), 14741486.

(26) Chaudhary, R.; Dhepe, P. L. Solid Base Catalyzed Depolymerization of Lignin into Low Molecular Weight Products. Green Chem. 2017, 19 (3), 778-788.

(27) Abdelaziz, O. Y.; Li, K.; Tunå, P.; Hulteberg, C. P. Continuous Catalytic Depolymerisation and Conversion of Industrial Kraft Lignin into Low-Molecular-Weight Aromatics. Biomass Convers. Biorefin. 2018, 8 (2), 455-470.

(28) Lyu, G.; Yoo, C. G.; Pan, X. Alkaline Oxidative Cracking for Effective Depolymerization of Biorefining Lignin to Mono-Aromatic Compounds and Organic Acids with Molecular Oxygen. Biomass Bioenergy 2018, 108, 7-14.

(29) Schutyser, W.; Kruger, J. S.; Robinson, A. M.; Katahira, R.; Brandner, D. G.; Cleveland, N. S.; Mittal, A.; Peterson, D. J.; Meilan, R.; Román-Leshkov, Y.; et al. Revisiting Alkaline Aerobic Lignin Oxidation. Green Chem. 2018, 20 (16), 3828-3844.

(30) Ma, R.; Guo, M.; Zhang, X. Recent Advances in Oxidative Valorization of Lignin. Catal. Today 2018, 302, 50-60.

(31) Abdelaziz, O. Y.; Meier, S.; Prothmann, J.; Turner, C.; Riisager, A.; Hulteberg, C. P. Oxidative Depolymerisation of Lignosulphonate 
Lignin into Low-Molecular-Weight Products with $\mathrm{Cu}-\mathrm{Mn} / \delta$-Al2O3.

Top. Catal. 2019. DOI: $10.1007 / \mathrm{s} 11244-019-01146-5$.

(32) Feghali, E.; Carrot, G.; Thuéry, P.; Genre, C.; Cantat, T. Convergent Reductive Depolymerization of Wood Lignin to Isolated Phenol Derivatives by Metal-Free Catalytic Hydrosilylation. Energy Environ. Sci. 2015, 8, 2734-2743.

(33) Huang, S.; Mahmood, N.; Tymchyshyn, M.; Yuan, Z.; Xu, C. C. Reductive De-Polymerization of Kraft Lignin for Chemicals and Fuels Using Formic Acid as an in-Situ Hydrogen Source. Bioresour. Technol. 2014, 171, 95-102.

(34) Behling, R.; Valange, S.; Chatel, G. Heterogeneous Catalytic Oxidation for Lignin Valorization into Valuable Chemicals: What Results? What Limitations? What Trends? Green Chem. 2016, 18 (7), $1839-1854$

(35) Santos, S. G.; Marques, A. P.; Lima, D. L. D.; Evtuguin, D. V.; Esteves, V. I. Kinetics of Eucalypt Lignosulfonate Oxidation to Aromatic Aldehydes by Oxygen in Alkaline Medium. Ind. Eng. Chem. Res. 2011, 50 (1), 291-298.

(36) Tarabanko, V. E.; Tarabanko, N. Catalytic Oxidation of Lignins into the Aromatic Aldehydes: General Process Trends and Development Prospects. Int. J. Mol. Sci. 2017, 18 (11), 2421.

(37) Rodrigues Pinto, P. C.; Borges Da Silva, E. A.; Rodrigues, A. E. Insights into Oxidative Conversion of Lignin to High-Added-Value Phenolic Aldehydes. Ind. Eng. Chem. Res. 2011, 50 (2), 741-748.

(38) Linger, J. G.; Vardon, D. R.; Guarnieri, M. T.; Karp, E. M.; Hunsinger, G. B.; Franden, M. A.; Johnson, C. W.; Chupka, G.; Strathmann, T. J.; Pienkos, P. T.; et al. Lignin Valorization through Integrated Biological Funneling and Chemical Catalysis. Proc. Natl. Acad. Sci. U. S. A. 2014, 111 (33), 12013-12018.

(39) Beckham, G. T.; Johnson, C. W.; Karp, E. M.; Salvachúa, D.; Vardon, D. R. Opportunities and Challenges in Biological Lignin Valorization. Curr. Opin. Biotechnol. 2016, 42, 40-53.

(40) Rodriguez, A.; Salvachúa, D.; Katahira, R.; Black, B. A.; Cleveland, N. S.; Reed, M.; Smith, H.; Baidoo, E. E. K.; Keasling, J. D.; Simmons, B. A.; et al. Base-Catalyzed Depolymerization of Solid Lignin-Rich Streams Enables Microbial Conversion. ACS Sustainable Chem. Eng. 2017, 5 (9), 8171-8180.

(41) Ravi, K.; Abdelaziz, O. Y.; Nöbel, M.; García-Hidalgo, J.; GorwaGrauslund, M. F.; Hulteberg, C. P.; Lidén, G. Bacterial Conversion of Depolymerized Kraft Lignin. Biotechnol. Biofuels 2019, 12, 56.

(42) Wei, Z.; Zeng, G.; Huang, F.; Kosa, M.; Huang, D.; Ragauskas, A. J. Bioconversion of Oxygen-Pretreated Kraft Lignin to Microbial Lipid with Oleaginous Rhodococcus Opacus DSM 1069. Green Chem. 2015, 17 (5), 2784-2789.

(43) Pfennig, N.; Lippert, K. D. Über Das Vitamin B12-Bedürfnis Phototropher Schwefelbakterien. Arch. Microbiol. 1966, 55 (3), 245256.

(44) Abdelaziz, O. Y.; Hulteberg, C. P. Physicochemical Characterisation of Technical Lignins for Their Potential Valorisation. Waste Biomass Valorization 2017, 8 (3), 859-869.

(45) Brunauer, S.; Emmett, P. H.; Teller, E. Adsorption of Gases in Multimolecular Layers. J. Am. Chem. Soc. 1938, 60 (2), 309-319.

(46) Barrett, E. P.; Joyner, L. G.; Halenda, P. P. The Determination of Pore Volume and Area Distributions in Porous Substances. I. Computations from Nitrogen Isotherms. J. Am. Chem. Soc. 1951, 73 (1), 373-380.

(47) Tolbert, A.; Akinosho, H.; Khunsupat, R.; Naskar, A. K.; Ragauskas, A. J. Characterization and Analysis of the Molecular Weight of Lignin for Biorefining Studies. Biofuels, Bioprod. Biorefin. 2014, 8 (6), $836-856$.

(48) Domínguez-Robles, J.; Tamminen, T.; Liitiä, T.; Peresin, M. S.; Rodríguez, A.; Jääskeläinen, A. S. Aqueous Acetone Fractionation of Kraft, Organosolv and Soda Lignins. Int. J. Biol. Macromol. 2018, 106, 979-987.

(49) Belkheiri, T.; Andersson, S.-I.; Mattsson, C.; Olausson, L.; Theliander, H.; Vamling, L. Hydrothermal Liquefaction of Kraft Lignin in Subcritical Water: Influence of Phenol as Capping Agent. Energy Fuels 2018, 32 (5), 5923-5932.
(50) Das, A.; Rahimi, A.; Ulbrich, A.; Alherech, M.; Motagamwala, A. H.; Bhalla, A.; da Costa Sousa, L.; Balan, V.; Dumesic, J. A.; Hegg, E. L.; et al. Lignin Conversion to Low-Molecular-Weight Aromatics via an Aerobic Oxidation-Hydrolysis Sequence: Comparison of Different Lignin Sources. ACS Sustainable Chem. Eng. 2018, 6 (3), 3367-3374.

(51) Araújo, J. D. P.; Grande, C. A.; Rodrigues, A. E. Vanillin Production from Lignin Oxidation in a Batch Reactor. Chem. Eng. Res. Des. 2010, 88 (8), 1024-1032.

(52) Pacek, A. W.; Ding, P.; Garrett, M.; Sheldrake, G.; Nienow, A. W. Catalytic Conversion of Sodium Lignosulfonate to Vanillin: Engineering Aspects. Part 1. Effects of Processing Conditions on Vanillin Yield and Selectivity. Ind. Eng. Chem. Res. 2013, 52 (25), 8361-8372.

(53) Yao, S. G.; Mobley, J. K.; Ralph, J.; Crocker, M.; Parkin, S.; Selegue, J. P.; Meier, M. S. Mechanochemical Treatment Facilitates Two-Step Oxidative Depolymerization of Kraft Lignin. ACS Sustainable Chem. Eng. 2018, 6 (5), 5990-5998.

(54) Bjelić, S.; Garbuio, L.; Arturi, K. R.; van Bokhoven, J. A.; Jeschke, G.; Vogel, F. Oxidative Biphasic Depolymerization (BPD) of Kraft Lignin at Low PH. Chemistry Select 2018, 3 (41), 11680-11686.

(55) Wu, W.; Dutta, T.; Varman, A. M.; Eudes, A.; Manalansan, B.; Loqué, D.; Singh, S. Lignin Valorization: Two Hybrid Biochemical Routes for the Conversion of Polymeric Lignin into Value-Added Chemicals. Sci. Rep. 2017, 7, 8420.

(56) Zakzeski, J.; Dębczak, A.; Bruijnincx, P. C. A.; Weckhuysen, B. M. Catalytic Oxidation of Aromatic Oxygenates by the Heterogeneous Catalyst Co-ZIF-9. Appl. Catal., A 2011, 394 (1-2), 79-85.

(57) Fernandes, M. R. C.; Huang, X.; Abbenhuis, H. C. L.; Hensen, E. J. M. Lignin Oxidation with an Organic Peroxide and Subsequent Aromatic Ring Opening. Int. J. Biol. Macromol. 2019, 123, 1044-1051.

(58) Piccolo, C.; Wiman, M.; Bezzo, F.; Lidén, G. Enzyme Adsorption on $\mathrm{SO} 2$ Catalyzed Steam-Pretreated Wheat and Spruce Material. Enzyme Microb. Technol. 2010, 46 (3-4), 159-169.

(59) Masai, E.; Katayama, Y.; Fukuda, M. Genetic and Biochemical Investigations on Bacterial Catabolic Pathways for Lignin-Derived Aromatic Compounds. Biosci., Biotechnol., Biochem. 2007, 71 (1), 1-15.

(60) Holder, J. W.; Ulrich, J. C.; DeBono, A. C.; Godfrey, P. A.; Desjardins, C. A.; Zucker, J.; Zeng, Q.; Leach, A. L. B.; Ghiviriga, I.; Dancel, C.; et al. Comparative and Functional Genomics of Rhodococcus Opacus PD630 for Biofuels Development. PLoS Genet. 2011, 7 (9), No. e1002219.

(61) Ravi, K.; García-Hidalgo, J.; Gorwa-Grauslund, M. F.; Lidén, G. Conversion of Lignin Model Compounds by Pseudomonas Putida KT2440 and Isolates from Compost. Appl. Microbiol. Biotechnol. 2017, 101 (12), 5059-5070.

(62) Zhang, S.; Winestrand, S.; Guo, X.; Chen, L.; Hong, F.; Jönsson, L. J. Effects of Aromatic Compounds on the Production of Bacterial Nanocellulose by Gluconacetobacter Xylinus. Microb. Cell Fact. 2014, 13,62 .

(63) Ravi, K.; García-Hidalgo, J.; Nöbel, M.; Gorwa-Grauslund, M. F.; Lidén, G. Biological Conversion of Aromatic Monolignol Compounds by a Pseudomonas Isolate from Sediments of the Baltic Sea. $A M B$ Express 2018, 8, 32.

(64) Wang, X.; Liang, Z.; Hou, J.; Bao, X.; Shen, Y. Identification and Functional Evaluation of the Reductases and Dehydrogenases from Saccharomyces Cerevisiae Involved in Vanillin Resistance. BMC Biotechnol. 2016, 16, 31.

(65) Chen, H.-P.; Chow, M.; Liu, C.-C.; Lau, A.; Liu, J.; Eltis, L. D. Vanillin Catabolism in Rhodococcus Jostii RHA1. Appl. Environ. Microbiol. 2012, 78 (2), 586-588.

(66) Karlson, U.; Dwyer, D. F.; Hooper, S. W.; Moore, E. R. B.; Timmis, K. N.; Eltis, L. D. Two Independently Regulated Cytochromes P-450 in a Rhodococcus Rhodochrous Strain That Degrades 2Ethoxyphenol and 4-Methoxybenzoate. J. Bacteriol. 1993, 175 (5), $1467-1474$.

(67) Eltis, L. D.; Karlson, U.; Timmis, K. N. Purification and Characterization of Cytochrome P450RR1 from Rhodococcus Rhodochrous. Eur. J. Biochem. 1993, 213 (1), 211-216. 
(68) Sutherland, J. B. Demethylation of Veratrole by Cytochrome P450 in Streptomyces Setonii. Appl. Environ. Microbiol. 1986, 52 (1), 98-100.

(69) Dardas, A.; Gal, D.; Barrelle, M.; Sauret-Ignazi, G.; Sterjiades, R.; Pelmont, J. The Demethylation of Guaiacol by a New Bacterial Cytochrome P-450. Arch. Biochem. Biophys. 1985, 236 (2), 585-592.

(70) Max, B.; Tugores, F.; Cortés-Diéguez, S.; Domínguez, J. M. Bioprocess Design for the Microbial Production of Natural Phenolic Compounds by Debaryomyces Hansenii. Appl. Biochem. Biotechnol. 2012, 168 (8), 2268-2284.

(71) de Gonzalo, G.; Colpa, D. I.; Habib, M. H. M.; Fraaije, M. W. Bacterial Enzymes Involved in Lignin Degradation. J. Biotechnol. 2016, 236, 110-119.

(72) Brzonova, I.; Kozliak, E. I.; Andrianova, A. A.; LaVallie, A.; Kubátová, A.; Ji, Y. Production of Lignin Based Insoluble Polymers (Anionic Hydrogels) by C. Versicolor. Sci. Rep. 2017, 7, 17507. 